\title{
A grande aceleração \& o campo comunicacional
}

\section{Lucia Santaella}

Doutora; Pontifícia Universidade Católica de São Paulo

Ibraga@pucsp.br

\section{Resumo}

Desde a revolução industrial que inaugurou, no campo da comunicação, a era da reprodutibilidade técnica, novas tecnologias midiáticas não cessam de emergir em um ritmo cada vez mais intenso até se tornar verdadeiramente avassalador a partir do advento do universo digital. Essa emergência crescente de tecnologias midiáticas não é um fenômeno isolado, mas deve ser inserida no contexto bem mais amplo daquilo que os especialistas em mudanças climáticas e geologia estão chamando de "grande aceleração". Para realizar tal inserção, este artigo tomou como roteiro metodológico o levantamento e estudo de dados bibliográficos, de um lado, relativos à evolução midiática desde a revolução industrial no século XIX até os nossos dias. De outro lado, relativos ao crescimento desmedido do gasto de fontes energéticas do planeta inteiramente imerso na circulação perversa do mercado capitalista. A comparação entre os dados tanto de um quanto de outro lado, conduziu esta pesquisa à constatação de uma interrelação indissolúvel entre ambos. Esse percurso nos leva à conclusão de que a aceleração midiática é parte integrante e contribui a seu modo para a grande aceleração que está levando o planeta Terra a uma nova era geológica.

\section{Palavras-chave}

Grande Aceleração. Antropoceno. Eras culturais. Gerações midiáticas.

\section{Introdução}

A "grande aceleração" é uma expressão que está sendo usada no âmbito da geologia, das mudanças climáticas e da crise ecológica do planeta. Ela foi enunciada por Will Stephen, da Universidade Nacional da Austrália, em uma entrevista para a BBC (FALCON-LANG, 2011). Tendo realizado gráficos para cartografar o crescimento das sociedades humanas a partir dos anos 1800, Steffen considerou bastante inesperado aquilo que encontrou: uma 
intensificação considerável da aceleração nesse crescimento desde a Segunda Guerra Mundial. Nesse contexto, o objetivo deste artigo é mapear brevemente a problemática do Antropoceno, uma nova idade geológica da Terra, para colocar em discussão as manifestações e extensões da "grande aceleração" também notáveis, inquietantes e perturbadoras no campo comunicacional.

\section{Antropoceno}

Em 1870, o geólogo italiano Antonio Stoppani propôs que o ser humano introduziu uma nova época na biosfera, que ele chamou de Antropozoica, no sentido de que as atividades humanas no planeta gradativamente se transformaram em uma força morfológica e geológica. Poucos cientistas lhe deram atenção. Desde então, a população humana no globo quadruplicou e seus impactos sobre a Terra foram se tornando cada vez mais óbvios. Para o biólogo E. O. Wilson, o padrão de crescimento da população no último século se aproxima do padrão de crescimento bacteriano (KOLBERT, 2011).

Algumas décadas mais tarde, em 1926, o geólogo russo V. I. Vernadsky reconheceu o poder crescente do humano sobre a biosfera. Tendo em vista que a tendência do crescimento caminhava na direção das influências das formas de pensamento sobre os ambientes, já em 1924, junto com o jesuíta francês Teilhard de Chardin e E. Le Roy, Crutzen e Stoermer chamaram de "noosfera" o mundo do pensamento, "[...] para marcar o crescente papel do poder da mente e dos talentos tecnológicos humanos para conformar seu futuro e ambientes." (2000, p. 17).

Foi só em 2000 que a denominação Antropoceno foi proposta por Paul Z. Crutzen, prêmio Nobel, em 1995, por seu trabalho sobre química atmosférica, e por Eugene F. Stoemer, em uma publicação do International Geosphere-Biosphere Pragramme. 0 que vem a ser o Antropoceno?

\section{Antropoceno: o humano na cena geológica}

Utilizando um método denominado estratigrafia, os especialistas avaliam sedimentos, mudanças preservadas nas rochas, desaparecimento e surgimento de novos fósseis, marcas glaciais, elevação das águas etc. para determinar as épocas, os períodos e as eras geológicas. Embora possam se estender por dezenas de milhões de anos, as épocas são relativamente mais curtas do que os períodos. Estes, como o período Cretáceo, são mais longos, enquanto 
as eras, como a Mesozoica, são ainda mais longas. Para não irmos muito longe, o Holoceno, no qual estamos inseridos, é uma época geológica pós-glacial, cujo início data de doze mil anos. Trata-se de uma época marcada, por exemplo, pelo advento da agricultura, então, pela formação de cidades, meios de comunicação e por novas formas de energia. Durante toda essa época, o regime climático estabilizou-se com climas temperados e os humanos se fizeram presentes em todos os continentes.

Oficialmente, continuamos no Holoceno, ou melhor, na era Cenozoica do Éon Fanerozoico, que se estende de 545 milhões de anos até os dias de hoje, e é caracterizado por abrigar a vida. O Fanerozoico é subdividido em três eras: o Paleozoico subdividido em seis períodos, o Mesozoico, subdividido em três períodos e o Cenozoico (do grego: kainos = recente + $z o e=$ vida) que teve início há 65 milhões de anos até os dias de hoje e se subdivide em dois períodos: o Terciário e o Quaternário. 0 Holoceno é uma época do período Quaternário.

Entretanto, nas últimas décadas, foi se criando um consenso entre os cientistas de que a biosfera deixou de se comportar dentro dos padrões do Holoceno: a atmosfera, o clima, os oceanos e o ecossistema estão todos operando fora das normas holocênicas. A antropoesfera, a camada humana que cresceu dentro da biosfera e suas pegadas sobre a Terra tornaram-se sobremaneira pesadas, o que está decididamente dando passagem a um novo período geológico que está sendo chamado de Antropoceno (do grego anthropos = ser humano + Kainos = recente, novo). Uma definição didática nos é oferecida pelo site Globaïa:

[0 Antropoceno] é um período marcado por um regime de mudança na atividade das sociedades industriais que teve início na virada do século XIX e que provocou rupturas globais no sistema da Terra em uma escala sem precedentes na história humana: mudança climática, perda da biodiversidade, poluição dos mares, terra e ar, depredação dos recursos, desnudamento da cobertura da terra, transformação radical da ecumene [palavra derivada de ecologia], entre outros (CARTOGRAPHY..., c2013).

Não existe um consenso relativo ao ponto exato de início desse novo período geológico. Poucos acreditam que tenha se iniciado com o advento da agricultura há oito mil anos e que levou hoje à cobertura de uma extensão de 38\% da terra não gelada do planeta. A maioria dos especialistas se distribui entre duas opções: final do século XVIII, com a revolução industrial, ou então 1945, depois da Segunda Guerra Mundial. No primeiro caso, a análise do ar mostra o início da concentração global crescente do dióxido de carbono e metano, o que coincide com a invenção da máquina a vapor, 1784, por James Watt. É a partir dessa data também que a expansão do ser humano, que, então, estava na margem de um bilhão, se fez acompanhar pela exploração dos recursos da Terra a ponto de se esperar que neste século a 
população chegue a dez bilhões de pessoas. As florestas tropicais desaparecem em um ritmo alarmante soltando dióxido de carbono e levando à extinção de várias espécies.

No segundo caso, sob a égide da "grande aceleração", 1945 é sinalizado como data inicial do Antropoceno. Foi essa época que marcou o surgimento da era nuclear e a assinatura radioativa que ela deixou sobre a superfície da Terra. Paralelamente, a economia global cresceu dez vezes em apenas algumas décadas. Mas uma das grandes preocupações nessa aceleração encontra-se na perda da biodiversidade, quando o ritmo de extinção das espécies da biosfera está correndo ao passo de cem a mil vezes mais rapidamente. Enfim, o grande problema é que, acompanhando esse ritmo, estamos consumindo exponencialmente mais recursos da natureza.

Oliveira (2015, doc. eletrônico) chama atenção para o fato de que

[...] o Antropoceno tem óbvias implicações biopolíticas, mas num sentido muito original. Pois o que se trata agora não é mais das vicissitudes da história de territórios e povos, de geos e politéia, mas de uma dupla conversão: a Terra se torna agente político, a política se torna agente geológico.

Até recentemente, o estudo das eras, épocas e períodos geológicos importava pouco para o restante dos campos de conhecimento e, certamente, importava menos para os leigos. Entretanto, se a revolução copernicana já foi capaz de transformar a visão humana sobre o ambiente em que vive, agora não há como deixar de compreender criticamente como o ser humano está implicado nos destinos do planeta. Diante de tudo isso, o tema do Antropoceno, nos últimos anos, deixou de ser privilégio dos especialistas, espalhando-se por várias áreas do conhecimento, inclusive das artes, e repercutindo cada vez mais intensamente nas mídias informativas, tais como jornais, revistas, TV e internet.

Ao propor a análise de uma grande aceleração também no campo da comunicação, este artigo não está certamente se colocando na posição ingênua de estabelecer uma comparação entre a geologia e a comunicação. Para começar, são eras, épocas e períodos incomensuravelmente distintos, o que breca qualquer ilusão de correspondência ou similitude. Contudo, um olhar retrospectivo para as mídias e linguagens comunicacionais humanas nos leva a constatar coincidentemente um fenômeno inegável de aceleração no seu crescimento, justo a partir da revolução industrial, com um ímpeto intensificado no seu ritmo a partir da Segunda Guerra Mundial e o advento da revolução digital. É sobre essa aceleração que este artigo irá discorrer no que se segue. 


\section{Seis eras culturais}

Para compreender a hipercomplexidade crescente da cultura desde que se deu o advento do computador como mídia das mídias, realizei uma incursão do passado remoto ao presente, tendo como meta determinar os tipos de formações culturais que nos precederam (SANTAELLA, 2003). Isso me levou a estabelecer seis tipos de lógicas culturais que, embora sejam historicamente sequenciais e distintas, foram gradativamente mesclando-se e interconectando-se de modo indissolúvel: a cultura oral, a escrita, a impressa, a cultura de massas, a cultura das mídias e a cultura digital.

Os critérios utilizados para chegar a essas seis formações culturais não foram muito distintos daqueles utilizados por outros autores que também estabeleceram suas divisões de acordo com o advento de tecnologias intelectuais que prefiro chamar de tecnologias de linguagem e de comunicação conformadoras dos ambientes sociais e culturais de cada época. É bem conhecida a divisão que Lévy (1993) chamou de três tempos do espírito: a oralidade primária, a escrita e a informática. Também é conhecida a divisão estabelecida por McLuhan (1972) entre a oralidade, a galáxia de Gutenberg e os meios massivos eletrônicos. Divisão um pouco mais detalhada aparece em um texto colaborativo do site New Media Literacies, que apresenta as seguintes etapas na evolução histórica dos sistemas de mídia: ancestral (cultura oral), residual (cultura impressa), dominante (cultura de massas) e emergente (cultura participativa). Para esse site, tais sistemas consistem de tecnologias comunicacionais e das mais variadas práticas econômicas, políticas, institucionais e culturais que crescem com eles.

A emergência de um novo sistema não desloca o que veio antes, mas adere como uma nova camada, tornando a ecologia midiática ainda mais estratificada. Apesar de aparentemente estar aí faltando a cultura visual, para os autores, sua história remonta já ao tempo da cultura oral e ela existe na órbita dos outros sistemas midiáticos. Assim, as pinturas nas cavernas coexistiram com a cultura oral, tapeçarias e vitrais fizeram a ponte entre a cultura oral e a impressa; os quadrinhos existem dentro da cultura impressa, mas também aparecem nos meios de massa, e assim por diante (SANTAELLA, 2010).

Embora apresentem semelhanças com as divisões acima mencionadas, as seis que foram por mim adotadas delas se distinguem, inclusive cheguei a elas de maneira independente, ao seguir a gradativa introdução histórica de novos meios de produção, armazenamento, memória, transmissão e recepção de linguagens no seio da vida social. Por já haver explicitado em mais de uma ocasião o perfil de cada uma dessas formações que também chamo de 
eras culturais, o que vale enfatizar no contexto deste artigo é a aceleração crescente no ritmo de passagem de uma era a outra. A era da oralidade teve início há quinhentos mil anos. As formas de escrita, pictográficas, ideogramáticas, hieroglíficas que emergiram primeiramente na Mesopotâmia há seis mil anos (NÖTH, 1990) passaram, no Ocidente, pela escritura alfabética, implantada no mundo grego, para virem a receber grande influxo reprodutor na invenção de Gutenberg no século XV. Esta permaneceu hegemônica por quatro séculos até a emergência da revolução industrial e o advento da cultura de massas que, sob uma outra ótica, é também chamada de indústria cultural.

A invenção da fotografia (1826), que deu início à reprodutibilidade técnica na base da cultura de massas cujo clímax foi alcançado em meados do século XX, foi seguida, depois de pouco mais de um século, no final dos anos 1960, pela cultura das mídias, quer dizer, as mídias informativas e programas de narrowcasting, o controle remoto, o videocassete, as videolocadoras, a televisão a cabo, as máquinas de xerox etc. começaram a relativizar a dominância da cultura de massas, ao mesmo tempo em que já vinham preparando o terreno para a avalanche da cultura digital nos processos de interatividade, seleção individual da informação e comunicação on-line por ela implantada.

De fato, ao estudar essas eras culturais, o que sempre me chamava muita atenção era perceber a aceleração no surgimento de novas tecnologias de linguagem ou sistemas de mídias e suas consequentes formações socioculturais, uma aceleração que, do século XIX para cá, foi se acentuando cada vez mais. Foi isso que me levou ao exame mais detalhado das gerações tecnológicas e midiáticas que tiveram início com a revolução industrial.

Da invenção da fotografia, explosão do jornal impresso, gravação sonora, telefonia e cinema que marcaram a industrialização da cultura e sua lógica massiva, até a década de 2010, no interior de cujo período realizei um estudo mais aproximado, constatei cinco gerações bem demarcadas, estas evidenciadoras de um ritmo crescente de aceleração (SANTAELLA, 2010).

\section{Cinco gerações midiáticas}

As cinco gerações midiáticas apareceram na seguinte sequência temporal: tecnologias eletromecânicas = cultura industrial massiva ou cultura do reprodutível (1826); tecnologias eletroeletrônicas, rádio e televisão, = cultura de difusão massiva $(1896 / 1936)$; tecnologias dos gadgets = cultura das mídias ou cultura do disponível (1970-80); tecnologias computa- 
cionais $=$ cultura do acesso (1990); tecnologias computacionais móveis = cultura da conexão contínua (2000) ${ }^{1}$.

As tecnologias eletromecânicas introduziram a reprodutibilidade técnica. Exemplos dessas mídias reprodutivas encontram-se nas linhas de produção dos jornais, nas câmeras fotográficas analógicas, nas filmadoras das primeiras gerações do cinema, telégrafos, telefones analógicos, entre outros. 0 advento do rádio e da televisão nos conduziu, então, ao período da difusão massiva que foi possibilitada pelas tecnologias de transmissão e baixo custo para o público, levando a cultura de massas ao seu clímax. A cultura do disponível, por sua vez, resultou de pequenos aparelhos ou gadgets como o controle remoto que, na sua aparente insignificância, transformou os modos de se assistir à TV, acentuados pela TV a cabo e o videocassete. No setor da escrita gutenberguiana, as máquinas de xerox permitiram ao usuário quebrar e se apossar de partes da informação impressa. São todos eles aparelhos que foram dando ao receptor a chance de buscar conteúdos de sua escolha.

Enquanto evoluíam as mídias na superfície da cultura, nos subterrâneos, o computador realizava sua escalada. Na década de 1930, deu-se o aparecimento teórico da máquina de Turing na sua busca por mecanizar o potencial do pensamento humano para o cálculo. Porém o processo de maturação dessa tecnologia foi longo, emergindo primeiro em máquinas pré-programadas, como calculadoras, para tomar forma mais definida em um suporte midiático programável, graças ao trabalho de Von Neumann na década de 1950. Essa nova arquitetura de hardware permitiu a implementação da máquina universal programável, na qual os programas - que, em última análise, viabilizam a comunicação - podem ser transmitidos e alterados com a mesma facilidade com que se alteram os conteúdos que apresentam.

Contudo, o grande impacto se deu com os computadores pessoais, ligados a redes teleinformáticas e suas interfaces gráficas para a interação amigável do usuário. Computadores pessoais e telefones já estavam aí se hibridizando em uma mesma arquitetura de hardware. Aos desktops seguiram-se os laptops que se miniaturizaram ainda mais nos iPads e iPhones, dando início, em curto espaço de tempo, à quarta geração (cultura do acesso: anos 1990) e, imediatamente a seguir, à quinta geração midiática (cultura da conexão contínua: anos 2000) que alguns chamam de hiperconexão, visto que, além de permitir a comunicação online, os dispositivos móveis permitem a conexão ininterrupta à internet, sem limites de espaço e de tempo.

\footnotetext{
${ }^{1}$ Nenhuma invenção acontece de chofre. Por isso, as datas são meramente aproximativas para dar a ideia daquilo que aqui interessa: o ritmo de aceleração.
} 
Essa sequencialidade, é preciso repetir, não significa que uma geração foi levando a outra ao desaparecimento. Ao contrário, nenhuma tecnologia da comunicação borra ou elimina as tecnologias anteriores. Elas se juntam na composição intrincadíssima de uma cultura hiper-híbrida. A cultura, que caracteriza o nosso tempo, nasce da mistura de todas as formas de cultura, inclusive das eras culturais (oral e escrita) anteriores ao aparecimento de Gutenberg e das gerações tecnológico-midiáticas desde a revolução industrial, de modo que todas elas estão hoje interconectadas.

0 que interessa colocar em relevo, contudo, é o processo de aceleração que, a partir dos anos 2000, foi se tornando estonteante. Em artigo publicado em 2012, busquei mapear o estado da arte dos avanços da internet. 0 período de ascensão dos equipamentos móveis coincidiu com a emergência borbulhante das redes sociais, Twitter, Facebook e outras (RECUERO, 2009). Isso se deu junto com a efervescência das wikis, blogs etc., período que justamente recebeu o nome de Web 2.0 (ANTOUN, 2008) para marcar as transformações pelas quais a lógica de funcionamento da internet estava passando. Mas quando o tempo corre célere, não poderia tardar para se dar a emergência da Web 3.0.

\section{As redes digitais de 2010 aos nossos dias}

Em 2010, eram várias as linhas de frente das mídias digitais: o estágio dos terabytes e petabytes, a computação em nuvem, a Web 3.0, a era da conexão onipresente e da mobilidade contínua, a computação ubíqua, pervasiva, senciente.

0 crescimento do volume informacional das redes foi se tornando desmedido, atingindo a escala dos petabytes que, em grego, quer dizer monstro. A quantidade é astronômica e não dá sinais de que deve parar por aí. Companheiro dos petabytes é o princípio da Cloud Computing que deriva da Computação em Grade (Grid Computing). Para alavancar a Grid Computing, algumas grandes empresas de tecnologia tais como Google, IBM e Microsoft mudaram a forma de utilização da Grid, oferecendo serviço de computação que é pago apenas por aquilo que se usa. Esse tipo de serviço foi rapidamente aceito pelos usuários domésticos e corporativos, uma iniciativa que transformou a Grid Computing em Cloud Computing 2 . Esta é baseada na utilização de memória, armazenamento e cálculos computacionais nos servi-

\footnotetext{
2 É preciso considerar que essa identificação da Grid com a Cloud Computing é simplificadora, pois tecnicamente existem, mesmo agora, diferenças entre grid e cloud ou nuvem. 0 termo "grid" costuma ser empregado para computação distribuída, cálculos divididos pelos computadores conectados mesmo que remotamente. Grid é uma variante on-line da arquitetura de sistemas em cluster (outro termo técnico), e é o mecanismo empregado, por exemplo, no @SETI e na criptomoeda bitcoin. Já "nuvem" ou "cloud" costuma ser empregado para armazenamento, seja de dados (Dropbox) ou software (caso da suíte MS Office 365).
} 
dores por meio do compartilhamento e da interligação da internet, acessível através de serviços oferecidos na Web (KOO, 2011). Um exemplo doméstico e simples da nuvem é o Dropbox.

Ao mesmo tempo, grandes transformações também foram se operando na superfície interativa das redes. Enquanto a Web 1.0 caracterizava-se pela conexão das informações presentes nos portais corporativos, portais de conteúdo, mecanismos de busca, websites, PIM (Personal Information Manager), PDAs, bases de dados e servidores de arquivos, a Web 2.0 passou a ter o foco no usuário. Por isso, suas aplicações democratizaram a web por meio da priorização dos conteúdos gerados e mantidos pela conectividade social. De fato, é a conectividade entre pessoas que caracteriza a Web 2.0 cujas tecnologias básicas são o groupware, as Wikis, os Weblogs, os portais de comunidades, o leilão eletrônico, a instant messaging e, certamente, as redes sociais que são as meninas dos olhos da Web 2.0.

Em plena explosão das redes sociais, a Web 2.0 já começou a se misturar com a 3.0, a Web semântica aliada à inteligência artificial por meio da qual a rede pretende organizar e fazer uso ainda mais inteligente do conhecimento já disponibilizado on-line. 0 conceito de Web 3.0 foi formulado, por exemplo, por O'Reilly (2007), Spivack $(2007,2009)$ e Wheeler (2010). As Webs 1.0 e 2.0 são Webs sintáticas, ou seja, as páginas são acessadas apenas pelo mecanismo de que a linguagem dispõe. Para achar a informação que buscamos, são usadas apenas as palavras que constam nas páginas procuradas, sem se recorrer a descrições adicionais (por exemplo, tags ${ }^{3}$ ) que interpretam os significados das palavras. Já a Web 3.0 é semântica porque as páginas na Web são acessadas a partir do seu significado e não apenas pelas palavras literais $(\mathrm{KOO}, 2011)$.

Concomitantemente à Web 2.0 e à 3.0, a cultura da mobilidade, baseada nos dispositivos móveis, aliados ao sistema de posicionamento global (GPS), explodiu de modo avassalador. Segundo Castells (1996, 2003), o universo digital é parte integrante da organização material, econômica, política das sociedades, sendo inclusive determinante nessa organização e significativa de sua real existência. Essa integração recebeu impulso com os aparelhos móveis incrementados nas mídias locativas, ou seja, mídias geolocalizadas.

A computação móvel e pervasiva (computadores em todos os lugares) é a chave para a compreensão das mídias locativas (LEMOS, 2011). No processo, o uso de sistemas de informação geográfica (GIS) espalhou-se das corporações e escritórios para as ruas e os campos, da administração pública e ambiental para um largo espectro de usos sociais. Além dos sis-

${ }^{3}$ São marcações nas palavras, figuras que adicionam significado ou as categorizam. 
temas de informação geográfica (GIS) e das tags de identificação de radiofrequência (RFID), a linguagem de marcação de geografia (GML-geographic markup language ${ }^{4}$ ), e o sensoriamento ambiental distribuído são utilizados nas mídias locativas.

Tanto quanto espaço e lugar, outro conceito que as mídias locativas trouxeram para o topo das considerações é o conceito de objeto que, na linguagem corrente, chamamos de coisas. Por meio de tecnologias como RFID e computadores inteligentes estamos no umbral de um mundo de dispositivos interconectados em rede que fornecem conteúdo relevante e informação para qualquer lugar em que o usuário esteja. Qualquer objeto, que costumamos chamar de coisas, entrará em faixas comunicacionais, anunciando o alvorecer de uma era em que a internet de hoje, de dados e de pessoas, conviverá com a internet das coisas. Colocar geotags nos objetos, de modo que esses objetos nos contem suas histórias, leva-nos a conhecer sua genealogia, seu enraizamento na matriz de produção. Estamos entrando, portanto, em um mundo em que, por estarem ligados a chips inteligentes, os objetos vão se tornar sencientes, quer dizer, conscientes das impressões dos sentidos, o que nos trará a possibilidade de um engajamento mais ativo entre o corpo, a cidade, os lugares e as coisas.

Tudo isso tem evoluído a passos largos para o estado atual dos avanços do universo digital cujo ritmo é tão assoberbante a ponto de não nos permitir mais pensar em gerações, conforme busquei sistematizar em 2010. Assim, neste momento em que escrevo, setembro de 2015, o imbróglio tecnológico encontra-se complexamente intrincado, em meio ao qual se destacam, na crista dos acontecimentos, os programas de big data (BOYD E CRAWFORD, 2012) para processar volumes gigantescos de dados e as smart cities, cidades inteligentes ou sencientes (TOWNSEND, 2013) para dar conta do gerenciamento, administração e controle geopolítico das excrecências urbanas em que se transformaram as metrópoles emergentes do século XIX.

\section{Do geopolítico ao ecopolítico}

A grande aceleração do campo comunicacional não foi aqui perfilada inocuamente. Trata-se agora de se perguntar que participação o campo midiático acaba por desempenhar na grande aceleração que nos conduziu ao Antropoceno. Sem dar respostas acabadas, pois

\footnotetext{
${ }^{4}$ Definida pelo Consórcio Geoespacial Livre, a $G M L$ utiliza $X M L$ para exprimir características geográficas. Pode servir de linguagem de modelação para sistemas geográficos e como um formato aberto para troca de informação geográfica. A marcação de dados é um conceito recente e envolve a codificação simples de sequências de dados em um arquivo de computador no formato texto-puro, ou seja, capaz de ser lido tanto por pessoas quanto por máquinas. Para esse fim, a linguagem mais utilizada atualmente é a $X M L$ e suas variantes.
} 
isso seria temerário, não é difícil perceber conexões, apesar da distância aparentemente incomensurável entre o campo da comunicação e a biosfera. Tecnologias midiáticas moldam e conformam todo o ambiente sociopolítico e cultural. Esses ambientes estão enraizados em modos de produção econômica que determinam as relações de produção. Portanto, trata-se aí de intersecções finas e intrincadas.

Desde a revolução industrial, que alguns colocam como ponto inicial da grande aceleração, intensificando-se no pós-Segunda Guerra Mundial, foi se consolidando aquilo que Hardt e Negri (2012) chamam de capitalismo cognitivo. Este está alicerçado no trabalho imaterial de uma economia do imaterial (LAZARATTO; NEGRI, 2001), fruto de transformações no modo de produção do capitalismo pós-industrial tal como foi devidamente explicitado por Hardt e Negri (2012) na obra Império. Transformação no modo de produção significa transformação na relação do trabalhador com seu trabalho, inclusive transformação na natureza do próprio trabalho e no conceito de força de trabalho. Enquanto na sociedade industrial taylorista/fordista, magistralmente retratada no filme Tempos modernos, de Chaplin, massas de trabalhadores eram reduzidas a tarefas repetitivas e automáticas, o capitalismo cognitivo desloca o trabalhador para tarefas qualitativas que têm sua base no conhecimento e na comunicação.

O papel que o campo comunicacional desempenha nessa nova fase do capitalismo global é relativamente evidente, não só porque se transformam as relações de produção, os atores e os objetos dessa produção, notoriamente simbólicos, portanto, de natureza comunicativa, mas também porque a sociedade do espetáculo intensificada, em que estamos mergulhados, exacerba a atração sedutora que o consumo fetichista de mercadorias, tão cego e inebriante quanto a paixão, desperta no ser humano, quaisquer que sejam suas faixas de renda. Há ofertas mercadológicas para os mais distintos tamanhos e estilos de bolsos.

Perseguir o papel que a multiplicação das mídias, inclusive que o universo midiático digital também desempenha nas novas formas de espetacularização do capitalismo cognitivo nos levaria longe demais para os propósitos deste artigo. Ademais, esse caminho, embora relevante, não me parece imprescindível para inferir que, não obstante a distância que parece separar os processos geológicos dos comunicacionais, o ritmo avassalador e ininterrupto de novas tecnologias midiáticas está inextricavelmente implicado, aliado e atado à grande aceleração que está conduzindo os destinos do Antropoceno. 


\section{Referências}

ANTOUN, Henrique (Org.). Web 2.0: participação e vigilância na era da comunicação distribuída. Rio de Janeiro: Mauad, 2008.

BOYD, Danah; CRAWFORD, Kate. Critical questions for big data. Information,

Communication \& Society, Abingdon , v. 15, n. 5, p. 662-679, 2012.

CARTOGRAPHY of the Anthropocene. c2013. Disponível em:

<http://globaia.org/portfolio/cartography-of-the-anthropocene/>. Acesso em: 25 nov. 2015.

CASTELLS, Manuel. La galaxia internet: reflexiones sobre internet, empresa y sociedad. Barcelona: Debolsillo, 2003.

CASTELLS, Manuel. The rise of the network society. New York: Blackwell, 1996.

CRUTZEN, Paul; STOERMER, Eugene F. The "anthropocene". IGBP Newsletter, n. 41, p. 17 18, May 2000. Disponível em:

<http://www.igbp.net/download/18.316f18321323470177580001401/NL41.pdf>. Acesso em 25 nov. 2015.

FALCON-LANG, Howard. Anthropocene: have humans created a new geological age?. 2011. Disponível em: <http://www.bbc.com/news/science-environment-13335683>. Acesso em: 10 ago. 2015.

HARDT, Michael; NEGRI, Antonio. Império. Rio de Janeiro: Record, 2012.

KOLBERT, Elizabeth. Enter the Anthropocene: age of man. 2011. Disponível em: <http://ngm.nationalgeographic.com/2011/03/age-of-man/kolbert-text>. Acesso em: 15 ago. 2015.

KOO, Lawrence. Web 3.0: impacto na sociedade de serviços. 2011. Tese (Doutorado em Comunicação e Semiótica) - Programa de Pós-Graduação em Comunicação e Semiótica, Pontifícia Universidade Católica de São Paulo, São Paulo, 2011.

LAZZARATO, Maurizio; NEGRI, Antonio. Trabalho imaterial. Rio de Janeiro: DP\&A, 2001.

LEMOS, André. Locative media and surveillance at the boundaries of informational territories. In: FIRMINO, Rodrigo J.; DUARTE, Fabio; ULTRAMARI, Clovis (Eds). ICTs for Mobile and ubiquitous urban infrastructure: surveillance, locative media and global networks. New York: Information Science Reference, 2011. p. 129-149

LÉVY, Pierre. Tecnologias da inteligência: o futuro do pensamento na era da informática. São Paulo: Editora 34, 1993.

McLUHAN, Marshall. A galáxia de Gutenberg. São Paulo: USP, 1972. 
NEW media literacies. Training Kids With Skills ForParticipatory Culture. 2007.Disponível em: <http://archive.turbulence.org/blog/archives/003631.html>. Acesso em: 10 ago 2015.

NÖTH, Winfried. Handbook of semiotics. Bloomington: Indiana University, 1990.

OLIVEIRA, Luiz Alberto. Antropoceno, objetos invisíveis, utopia. 2015. Disponível em: $<$ http://www.mutacoes.com.br/sinopses/antropoceno-objetos-invisiveis-utopia/>. Acesso em: 30 ago. 2015.

O'REILLY, T. Today's Web 3.0 nonsense blogstorm. 2007. Disponível em:

<http://radar.oreilly.com/archives/2007/10/web-30-semantic-web-web-20.html >. Acesso em: 17 mai. 2011.

RECUERO, Raquel. As redes sociais na internet. Porto Alegre: Sulina, 2009.

SANTAELLA, Lucia. A ecologia pluralista da comunicação: conectividade, mobilidade, ubiquidade. São Paulo: Paulus, 2010.

SANTAELLA, Lucia. Culturas e artes do pós-humano: da cultura das mídias à cibercultura. São Paulo: Paulus, 2003.

SPIVACK, N. A new economic framework for content in Web 3.0. 2009. Disponível em: $<$ http://novaspivack.typepad.com/nova_spivacks_weblog/2009/11/a-new-economicframework-for-content-in-web-30.html>. Acesso em: 29 nov. 2010.

SPIVACK, N. Making sense of the Semantic Web and, twine. 2007. Disponível em: <http://novaspivack.typepad.com/nova_spivacks_weblog/2007/11/making-senseof.html>. Acesso em: 29 nov. 2010.

TOWNSEND, Anthony M. Smart cities: big data, civic hackers, and the quest for a new utopia. New York: W. W. Norton \& Company, 2013.

WHEELER, S. Web 3.0: the way forward? 2010. Disponível em: http://www.authorstream.com/Presentation/aSGuest76768-688449-web3-0-the-wayforward/ Acesso em: 20 out. 2010. 


\title{
The Great Aceleration \& the Comunicational
} field

\begin{abstract}
Since the industrial revolution that ushered, in the field of communication, the era of mechanical reproduction, new media technologies are constantly emerging at an increasingly rapid pace to become truly overwhelming from the advent of the digital universe on. This growing emergency of media technologies is not an isolated phenomenon, but should be inserted in the much broader context of what the specialists in climate change and geology are calling the "great acceleration". To conceive of this integration, this article took as its methodological outline the survey and study of bibliographic data, on the one hand, on the evolution of media since the industrial revolution in the nineteenth century to the present day. On the other hand, data concerning the excessive spending of the planet energy sources which results from its insertion in the perverse circulation of the capitalist market. A comparison of the data from both conducted this research to finding an indissoluble interrelation between them. This leads us to the conclusion that media acceleration is part and contributes in its own way to the big acceleration that is leading Earth to a new geological era.
\end{abstract}

\section{Keywords}

Great acceleration. Anthropocene. Cultural eras. Midia generations.

Recebido em 23/09/2015

Aceito em 15/12/2015 